\title{
Laparoscopy or fast-track surgery, or both?
}

\author{
K. Slim · A. Fingerhut
}

Published online: 22 January 2009

(C) Springer Science+Business Media, LLC 2009

There is no doubt that the laparoscopic revolution could be considered one of the major improvements for the management of colorectal diseases. Since its introduction in the 1990s, several meta-analyses have clearly demonstrated its feasibility and efficacy $[1,2]$. It is becoming the new "gold standard" for the care of colonic diseases with a high level of evidence [3] because of its mini-invasiveness and better postoperative comfort for surgical patients. At the same time, another improvement in colorectal surgery, initiated by Kehlet and coworkers, the so-called enhanced recovery protocol or the fast-track surgery (FTS) approach [4, 5], initially less recognized, has gradually gained worldwide acceptance [6]. This new paradigm, a parallel revolution in the care of surgical patients (based on a multimodal approach of patients), was initiated in the field of open surgery. However, the evidence-based literature shows with a high level of evidence that FTS is feasible, safe, and offers a better postoperative recovery compared with traditional care [5], even for laparoscopic surgery.

Generally speaking, beside the field of colorectal surgery, one of the most important lessons learned from the laparoscopic revolution has been that some of the old dogma has to be questioned: this has sparked a review of

K. Slim $(\bowtie)$

Department of Digestive Surgery, University Hospital Clermont-

Ferrand (CHU), Hotel-Dieu Boulevard Leon Malfreyt,

Clermont-Ferrand, France

e-mail: kslim@chu-clermontferrand.fr

\section{A. Fingerhut}

Department of Digestive Surgery, Roissy, France

A. Fingerhut

Department of Surgery, University of Athens,

Hippokration Hospital, Athens, Greece several practices in open surgery. As an example, surgical stress and inflammatory response to surgery have been better evaluated and cell-mediated immunosuppression has been highlighted as an important component in this setting [7]. Thanks to the laparoscopic approach, "modern open" surgery also has become less "aggressive."

\section{Two alternatives for colorectal surgery}

We are now faced with two alternative options, both designed to improve perioperative surgical care: "traditional" laparoscopic surgery and "open" FTS.

It is noteworthy that in the major, randomized trials [811] that served to establish the superiority of laparoscopic colon surgery compared with its open counterpart, the control patients underwent open traditional approach without FTS - the standard when those trials were initiated. Therefore, from an evidence-based point of view, one can only say that laparoscopic surgery is superior to open surgery as it was conceptualized in the 1990s. Without trials comparing traditional laparoscopic surgery to open FTS, whether there is sound evidence that the traditional laparoscopic surgery is superior to open FTS remains to be shown.

When we consider the respective results of these two approaches and compare for example the length of postoperative hospital stay (LOS), the results of randomized trials on conventional laparoscopic surgery (without a multimodal perioperative approach) were never superior to those of FTS. Indeed, LOS is an outcome subjected to variations related to socioeconomic factors, but all published large trials showed concordant results with a mean LOS exceeding 5 days in all cases [8-11], whereas in most randomized trials on "open" FTS, the mean LOS did not exceed 5 days [references on request to KS]. 
Intuitively, one can assume that combining the two approaches would be beneficial; however, this assumption is not evidence-based because no published trial has yet compared traditional laparoscopy with laparoscopy within a multimodal rehabilitation protocol.

\section{The role of laparoscopy in colorectal FTS}

Another way to resolve this issue would be to evaluate the impact of the laparoscopic approach within an FTS protocol, which has been done in two randomized trials from Denmark [12] and the United Kingdom [13]. The protocols were similar; however, unfortunately for those awaiting the results, these trials showed conflicting results. The blinded trial by Basse et al. [12] was unable to show any difference between laparoscopic and open colorectal surgery within a multimodal rehabilitation protocol, as regards LOS or functional recovery. The other trial [13], which was not blinded, suggested a superiority of laparoscopy (LOS significantly shorter: 5.2 vs. 7.4 days, and better performance score in day 2), but one cannot exclude a placebo effect due to the absence of blinding. These conflicting results have also been reported in non randomized studies.

Therefore, the current body of evidence cannot resolve this issue. The role of laparoscopy in this setting remains controversial, and we still do not know whether there are actual advantages of integrating laparoscopy in a multimodal rehabilitation. One can assume that the main difference between laparoscopy and laparotomy in the setting of FTS could finally be a lower rate of incisional hernia after the laparoscopic access, but this has yet to be proven (the scanty evidence that we have today does not suggest this). Furthermore, several questions remain to be answered regarding the cost-effectiveness of fast-track laparoscopy compared with fast-track laparotomy. The ongoing LAFA trial [14] could answer these questions, and its results are eagerly awaited.

\section{References}

1. Schwenk W, Haase O, Neudecker J, Müller JM (2005) Short term benefits for laparoscopic colorectal resection. Cochrane Database Syst Rev (3):CD003145
2. Bonjer HJ, Hop WC, Nelson H, Sargent DJ, Lacy AM, Castells A, Guillou PJ, Thorpe H, Brown J, Delgado S, Kuhrij E, Haglind E, Påhlman L, Transatlantic Laparoscopically Assisted vs Open Colectomy Trials Study Group (2007) Laparoscopically assisted vs open colectomy for colon cancer: a meta-analysis. Arch Surg 142:298-303

3. Slim K, Chipponi J (2006) Laparoscopic surgery today. Br J Surg 93:779-780

4. Kehlet H, Dahl JB (2003) Anaesthesia, surgery, and challenges in postoperative recovery. Lancet 362:1921-1928

5. Kehlet H (2008) Fast-track colorectal surgery. Lancet 371:791793

6. Kehlet H, Büchler MW, Beart RW Jr, Billingham RP, Williamson R (2006) Care after colonic operation: is it evidence-based? Results from a multinational survey in Europe and the United States. J Am Coll Surg 202:45-54

7. Lin E, Calvano SE, Lowry SF (2000) Inflammatory cytokines and cell response in surgery. Surgery 127:117-126

8. Clinical Outcomes of Surgical Therapy Study Group (2004) A comparison of laparoscopically assisted and open colectomy for colon cancer. N Engl J Med 350:2050-2059

9. Veldkamp R, Kuhry E, Hop WC, Jeekel J, Kazemier G, Bonjer HJ, Haglind E, Påhlman L, Cuesta MA, Msika S, Morino M, Lacy AM, COlon cancer Laparoscopic or Open Resection Study Group (COLOR) (2005) Laparoscopic surgery versus open surgery for colon cancer: short-term outcomes of a randomised trial. Lancet Oncol 6:477-484

10. Guillou PJ, Quirke P, Thorpe H, Walker J, Jayne DG, Smith AM, Heath RM, Brown JM, MRC CLASICC trial group (2005) Shortterm endpoints of conventional versus laparoscopic-assisted surgery in patients with colorectal cancer (MRC CLASICC trial): multicentre, randomised controlled trial. Lancet 365:1718-1726

11. Hewett PJ, Allardyce RA, Bagshaw PF, Frampton CM, Frizelle FA, Rieger NA, Smith JS, Solomon MJ, Smith JH, Stevenson ARL (2008) Short-term outcomes of the Australasian randomized clinical study comparing laparoscopic and conventional open surgical treatments for colon cancer. The ALCCaS Trial. Ann Surg 248:728-738

12. Basse L, Jakobsen DH, Bardram L, Billesbølle P, Lund C, Mogensen T, Rosenberg J, Kehlet H (2005) Functional recovery after open versus laparoscopic colonic resection: a randomized, blinded study. Ann Surg 241:416-423

13. King PM, Blazeby JM, Ewings P, Franks PJ, Longman RJ, Kendrick AH, Kipling RM, Kennedy RH (2006) Randomized clinical trial comparing laparoscopic and open surgery for colorectal cancer within an enhanced recovery programme. Br J Surg 93:300-308

14. Wind J, Hofland J, Preckel B, Hollmann MW, Bossuyt PM, Gouma DJ et al (2006) Perioperative strategy in colonic surgery; Laparoscopy and/or FAst track multimodal management versus standard care (LAFA trial). BMC Surg 6:16 